\title{
Identificação das fases do processo de morrer pelos profissionais de Enfermagem
}

\author{
Identification of the dying process phases by Nursing professionals \\ La identificación de las fases del proceso de muerte para los profesionales de Enfermería
}

Tatiana Thaller Susaki ${ }^{1}$, Maria Júlia Paes da Silva ${ }^{2}$, João Francisco Possari ${ }^{3}$

\begin{abstract}
RESUMO
Objetivo: verificar se o enfermeiro consegue identificar as cinco fases do processo de morrer, descritas por Elizabeth Kübler-Ross, nos pacientes sob seus cuidados e que se encontram fora de possibilidades terapêuticas. Métodos: foi questionado se percebem os sinais da comunicação não-verbal para prestar esse atendimento e fazer essa identificação. Os dados foram coletados em janeiro de 2004 por meio de entrevista individual, pré-agendada, com enfermeiros, em hospital público vinculado ao ensino na cidade de São Paulo. Resultados: constatamos que $92 \%$ dos enfermeiros conseguiram identificar pelo menos uma das fases do processo de morrer na vivência com pacientes terminais, sendo citadas, em média, três. A aceitação (85\%), a negação $(69 \%)$ e a depressão $(61 \%)$ são as mais freqüentemente percebidas. Verificamos o uso e entendimento da comunicação não-verbal na identificação das fases nas falas de $54 \%$ dos enfermeiros. Conclusão: os resultados também evidenciaram as dificuldades enfrentadas pelo enfermeiro quanto essa temática e, percebe-se que existe uma lacuna evidente entre a formação do profissional e a manutenção do seu treinamento e suporte na instituição de saúde.
\end{abstract}

Descritores: Morte; Morrer; Enfermagem; Comunicação não-verbal; Cuidados paliativos

\begin{abstract}
Objective: to verify if the nurses could to identify the five dying process phases, described by Elizabeth Kübler-Ross, in patients under their cares and out of therapeutic possibilities. Methods: were questioned if can notices the non-verbal communication signs to render that attendance and to do that identification. The data were collected in January of 2004 by means of individual interview, with nurses, in public hospital linked to the teaching in the city of São Paulo. Results: we verified that $92 \%$ of the nurses got to identify at least one of the dying process phases in their experiences with terminals patients, were mentioned, on the average, three. The acceptance (85\%), the denial $(69 \%)$ and the depression (61\%) were more frequently the noticed. We verified the use and understanding of the non-verbal communication in the identification of the phases in the speeches of $54 \%$ of the nurses. Conclusion: the results evidenced the difficulties faced by the nurse about this thematic.
\end{abstract}

Descriptors: Death; Dying; Nursing; Non-verbal communication; Palliative care

\section{RESUMEN}

Objetivo: verificar a la enfermera consigue identificar las cinco fases del proceso de muerte, descrito por Elizabeth Kübler-Ross, en los pacientes bajo sus cuidados y esa reunión fuera de posibilidades terapéuticas. Métodos: fue cuestionado si nota las señales de la comunicación no-verbal para dar esa asistencia y hacer esa identificación. Los datos eran reunido en enero de 2004 por medio de la entrevista individual, pré-agendada, con enfermeras, en hospital público se unido a la enseñanza en la ciudad de São Paulo. Resultados: verificamos que $92 \%$ de las enfermeras consiguieron identificar uno de las fases del proceso de muerte en la existencia con términos de los pacientes por lo menos, mencionándose, en promedio, tres. La aceptación (85\%), el rechazo (69\%) y la depresión (61\%) ellos frecuentemente son más los notaron. Nosotros verificamos el uso y entendiendo de la comunicación no-verbal en la identificación de las fases en los discursos de $54 \%$ de las enfermeras. Conclusión: los resultados evidenciaron las dificultades enfrentadas por la enfermera como ese temático.

Descriptores: La muerte; Morirse; Enfermería; Comunicación no verbal; Cuidados paliativos

\footnotetext{
1. Enfermeira graduada pela Escola de Enfermagem da Universidade de São Paulo - USP - São Paulo (SP), Brasil.

2. Professora Titular do Departamento de Enfermagem Médico-Cirúrgica da Escola de Enfermagem da Universidade de São Paulo - USP - São Paulo (SP), Brasil.

3. Enfermeiro e Diretor Técnico de Serviço do Hospital das Clínicas de São Paulo - HC - São Paulo (SP), Brasil.
} 


\section{INTRODUÇÃO}

O paciente fora de possibilidades terapêuticas é rotulado como "terminal". Isso traz a falsa idéia de que nada mais pode ser feito. Porém, o paciente em fase terminal está vivo e tem necessidades especiais que, se os profissionais de saúde estiverem dispostos a descobrir quais são, podem ser atendidas e proporcionarão conforto durante essa vivência ${ }^{(1-2)}$.

Neste contexto, faz-se importante na inclusão e adoção dos denominados Cuidados Paliativos à prática assistencial às pessoas fora de possibilidades terapêuticas. $\mathrm{O}$ conceito que melhor explica este seguimento se dá pela Organização Mundial da Saúde( ${ }^{(3)}$ que definiu os cuidados paliativos como: uma abordagem que aprimora a qualidade de vida, dos pacientes e familiares, que enfrentam problemas associados com doenças ameaçadoras de vida, através da preservação e alivio do sofrimento por meio da identificaşão precoce, avaliação correta e tratamento da dor e de outros problemas de ordem física, psicossocial e espiritual. A definição da OMS explicita também que os cuidados paliativos: afirmam a vida e encaram a morrer como um processo normal; não apressam a morte; procuram aliviar a dor e outros sintomas desconfortáveis; integram os aspectos psicossocial e espiritual nos cuidados do paciente; oferecem um sistema de apoio para ajudar a família a lidar durante a doença do paciente e no processo do luto $^{(3-4)}$. A filosofia dos cuidados paliativos tem apresentado uma movimentação crescente dentro da equipe multidisciplinar de saúde, bem como um papel diferenciado no contexto assistencial, das políticas de saúde e currículos voltados à formação de profissionais da área ${ }^{(5)}$.

No âmbito da saúde, há um crescente desenvolvimento de estudos, pesquisas e instrumentos que auxiliam o profissional a promover o aperfeiçoamento de suas habilidades e capacitação no atendimento ao paciente fora de possibilidades terapêuticas. Esta produção científica torna-se uma ferramenta valorosa para a prática assistencial, beneficiando tanto os profissionais, quanto os pacientes e seus familiares ${ }^{()}$. O enfermeiro que agrega os conhecimentos tecno-científicos de cuidado a esse tipo de paciente na sua prática, possibilita a viabilização da ortotanásia (o morrer bem e tranqüilo) e evita a eutanásia e a distanásia, que se tornam uma agressão à dignidade humana ${ }^{(4)}$.

Elizabeth Kübler-Ross foi a pioneira em descrever as atitudes e reações emocionais suscitadas pela aproximação da morte em pacientes terminais, reações humanas que não dependem de um aprendizado só $\operatorname{cultural}^{(7)}$. Seus trabalhos descrevem a identificação dos cinco estágios que um paciente pode vivenciar durante sua terminalidade, que são: negação, raiva, barganha, depressão e aceitação(1).

A negação pode ser uma defesa temporária ou, em alguns, casos pode sustentar-se até o fim. O paciente desconfia de troca de exames ou competência da equipe de saúde. Geralmente o pensamento que traduz essa defesa é: "não, eu não, é verdade".

A raiva é a fase na qual surgem sentimentos de ira, revolta, e ressentimento: "porquê eu?". Torna-se mais difícil lidar com o paciente, pois a raiva se propaga em todas as direções, projetando-se no ambiente, muitas vezes, sem "razão plausível". Já na barganba o doente faz promessas por um prolongamento da vida ou alguns dias sem dor ou males físicos. As barganhas são feitas com Deus, na maioria das vezes e, psicologicamente, podem estar associadas a uma culpa recôndita.

A depressão pode evidenciar seu alheamento ou estoicismo, com um sentimento de grande perda. As dificuldades do tratamento e hospitalização prolongados aumentam a tristeza que, aliada a outros sentimentos, ocasionam a depressão.

A aceitação é aquela em que o paciente passa a aceitar a sua situação e seu destino. É o período em que a família pode precisar de ajuda, compreensão e apoio, à medida que o paciente encontra uma certa paz e o círculo de interesse diminui. No entanto, há pacientes que mantém o conflito com a morte, sem atingir esse estágio.

Não há uma ordem para a ocorrência dessas manifestações, tão pouco uma cronologia, sendo que o paciente pode vivenciar mais de uma destas fases, concomitantemente, num mesmo período ou até mesmo não vivenciar algumas delas.

Estas fases são como mecanismos de defesa para enfrentar o processo desconhecido do morrer, em que os conflitos de ordem emocional, material, psicológica, familiar, social, espiritual, entre outros, surgem de forma acentuada, afetando diretamente o relacionamento com a equipe de saúde ${ }^{(1-2,8)}$.

É também relevante o aspecto emocional dos profissionais de saúde, pois esses também criam mecanismos de defesa que os auxiliam no enfrentamento da morte e do processo de morrer. Por serem preparados para a manutenção da vida, a morte e o morrer, em seu cotidiano, suscitam sentimentos de frustração, tristeza, perda, impotência, estresse e culpa. Em geral, o despreparo leva o profissional a afastar-se da situação ${ }^{(2,9-10)}$.

A Enfermagem tem como estabelecer uma comunicação mais estreita a partir da relação do cuidado e, por conseqüência, conhecer melhor o paciente como pessoa, pois encontra-se mais presente durante o estágio terminal $^{(6,8,10-12)}$.

As solicitações dos pacientes em estágio final, algumas vezes, são difíceis de se compreender, e por isso o enfermeiro deve possuir os conhecimentos e habilidades de comunicação para decodificar informações essenciais, diminuindo a aflição de quem está morrendo e proporcionando um cuidado de qualidade ${ }^{(10-11)}$.

Neste contexto, as habilidades de comunicação para abordar o processo de morte são um instrumento 
necessário que viabiliza ao profissional identificar qual das cinco fases do processo de morrer, como indicam os trabalhos de Kübler-Ross ${ }^{(1)}$, o paciente se encontra, e assim, auxiliar de forma qualitativa e integral na sua assistência.

A comunicação se manifesta na relação paciente-equipe de saúde de diversas formas, podendo ser verbalizada ou não. O enfermeiro deve saber relacionar-se e trabalhar com a comunicação não-verbal, em que palavras são, às vezes, substituídas pelo comportamento e atitudes que revelam a vivência do paciente; outras vezes, complementadas pelo comportamento e, outras vezes, contraditas $^{(13)}$.

A comunicação não-verbal ocorre na interação pessoapessoa e caracteriza-se pela transmissão da informação por meio de gestos, posturas, expressão facial, orientações do corpo, entre outras particularidades ${ }^{(13)}$. A comunicação com pacientes fora de possibilidades terapêuticas geralmente está prejudicada devido às reações emocionais abruptas deste período, bem como ao uso de sedativos e morfínicos no alívio da dor. A comunicação não-verbal potencializa a transmissão da mensagem e diminuí as dificuldades de verbalização comuns nos processos de morte ${ }^{(10)}$.

\section{OBJETIVOS}

* Verificar se o enfermeiro consegue identificar as cinco fases do processo de morrer, descritas por Kübler-Ross, nos pacientes sob seus cuidados;

* Verificar se o enfermeiro utiliza-se da comunicação não-verbal para a identificação dessas fases.

\section{MÉTODOS}

Trata-se de um estudo quanti-qualitativo, descritivo e exploratório, realizado na unidade de Hematologia de um hospital geral público e vinculado ao ensino do Município de São Paulo, onde o índice de pacientes fora de possibilidades terapêuticas é bastante elevado (aproximadamente $40 \%$ ). Foram entrevistados 13 enfermeiros, de um total de 14 , que trabalham na unidade citada.

Após aprovação pela Comissão de Ética e Pesquisa do referido hospital, esclarecimento e autorização dos sujeitos da pesquisa por escrito, através de um Termo de Consentimento Livre e Esclarecido utilizado na Instituição, a coleta de dados ocorreu em janeiro de 2004, mediante entrevista previamente agendada com uma das pesquisadoras, realizada individualmente, em local reservado, na unidade de atuação dos profissionais. Para orientar a entrevista, as questões norteadoras elaboradas foram: Que comportamentos e falas nos pacientes que estão morrendo vocêpercebe? Você as identifica com as fases discutidas por Elizabeth
Kübler-Ross? Inicialmente, questões como idade, tempo de experiência na profissão e com pacientes terminais, além de treinamento sobre o tema foram feitas, para o aquecimento da entrevista e melhor compreensão das respostas oriundas das questões temáticas. As entrevistas foram gravadas e transcritas na íntegra, para posterior análise.

Os dados foram agrupados por freqüência de aparecimento da resposta de natureza expressiva do discurso, com base no referencial teórico utilizado ${ }^{(14)}$, na formação de códigos que denotam como se dá a identificação do enfermeiro das fases do processo de morrer. Foram citados trechos das respostas para ilustrar os resultados.

\section{RESULTADOS}

A equipe de enfermagem da unidade de Hematologia é composta por indivíduos com idades entre 24 a 49 anos, sendo a média de 38,7 anos. O tempo médio de experiência profissional em Enfermagem foi de 13,4 anos, variando de 2 a 29 anos; e o tempo médio de experiência com pacientes terminais foi de 8,6 anos, variando entre 1 a 15 anos. A partir dessas características percebe-se que os enfermeiros participantes do estudo e que trabalham com pacientes fora de possibilidades terapêuticas, compõem uma equipe heterogênea de profissionais que possuem tempos diferentes de experiências com pacientes terminais.

Observa-se que $10(77 \%)$ dos entrevistados negaram qualquer treinamento num primeiro momento. Porém, nos discursos, alguns enfermeiros referem a participação em dinâmicas de grupo, cursos rápidos e palestras sobre a temática, mas não consideraram essas experiências como uma forma de treinamento para os cuidados paliativos. Muitos creditam o conhecimento utilizado na prática como fruto da experiência cotidiana. Todos os enfermeiros apresentaram, em falas posteriores, conhecimentos sobre o tema e indicam que suas ações estão baseadas em suas experiências profissionais, pois não relacionam o conhecimento tanatológico a um treinamento realizado.

Dentre os entrevistados, três $(23 \%)$ referiram ter recebido algum tipo de treinamento durante a graduação ou na vida profissional considerando-o escasso e não continuado ou sistematizado.

Mecanismos de defesa interferindo na identificação do enfermeiro

Percebe-se que seis $(46 \%)$ dos enfermeiros manifestaram mecanismos de defesa no enfretamento das situações de morte, em seus discursos, semelhantes àquele citado por Kübler-Ross ${ }^{(1)}$ nos pacientes fora de possibilidades terapêuticas. Isso demonstra a dificuldade desses profissionais em exercer o seu trabalho mediante 
o despreparo e desamparo a que estão sujeitos.

Então, existem os pacientes que só no jeito de agir, a maneira de falar, como está revoltado, está revoltado, porque tem que estar revoltado, mesmo. (E2)

Nesse discurso percebe-se como o enfermeiro, sensibilizado pela temática do morrer, transfere à representação do paciente os sentimentos negativos suscitados ao imaginar a própria terminalidade. Essa reação do profissional já foi advogada por outros autores $^{(2,15)}$ que demonstraram como isso pode modificar o comportamento humano.

As dificuldades e sofrimentos podem se canalizar em reações semelhantes à fase da ira ${ }^{(1)}$ e expressam a inconformidade e sentimento de impotência do profissional:

Não. É difícil. O que você fala pra uma pessoa que fala: "Por que comigo?", o que você fala pra uma mãe de uma criança que fala assim: "Meu único filho e Deus está me castigando!". Não é fácil manter uma relação com a morte! Não é fácil manter uma relação com a familia! Não é fácil manter uma relação com os mais jovens! O que você fala numa hora dessas?! Então, é melhor ouvir porque você não tem o que falar. Eu sou católica. Mas assim... justifica o que, quando é um jovem. Para a gente, também é um desconforto muito grande. (E10)

No mesmo discurso também nota-se a citação do enfrentamento da morte sustentado pela base religiosa que pode ser compreendida como a manifestação da barganha pelo enfermeiro e, que de certa forma, ameniza o sofrimento do profissional diante da situação de morte, isentando-o de uma maior responsabilidade, constituindo um mecanismo de defesa para a realidade inexorável da morte de cada um, bem como do fracasso terapêutico ${ }^{(15)}$.

\section{Identificando as fases do processo de morrer}

As fases identificadas com maior freqüência foram: a aceitação, a negação e a depressão. A fase da aceitação no comportamento e nas reações dos pacientes foi referida por $11(85 \%)$ dos enfermeiros da unidade. O comportamento que demonstra a intencionalidade de despedida foi uma das bases para compreender esta fase no processo de morrer ${ }^{(1)}$. Nesse sentido, percebe-se na fala dos enfermeiros que identificaram essa fase uma nítida percepção de como os pacientes expressam esse comportamento.

O último que nós tivemos assim foi mais marcante. Foi um que pediu para se despedir de toda a familia, pediu para se despedir de todo mundo. Ele estava bem consciente. Então, eles pedem pra se despedir. (E4)

A negação é a segunda fase melhor percebida pelos enfermeiros sendo constatada em $9(69 \%)$ das entrevistas.

Eu me lembro que teve uma paciente que quando entrou aqui, também negava. Ela falava assim: "Não!", ela era bem evangélica, "Não! Imagina! É tudo mentira isso que o médico falou! Deus já me anunciou que eu não tenho essa doença, é tudo mentira do médico". (E4)

A depressão foi expressa em 8 (61\%) das entrevistas, sendo mais comumente percebida através da falta de cooperação ou de interesse dos pacientes pelo tratamento, atitudes de apatia, o ficar quieto, e a falta de atividades. O comportamento do paciente pode "perturbar" a rotina de trabalhos da equipe já despreparada para lidar com esse tipo de situação e, por isso, a depressão é mais facilmente evidenciada como uma quebra de rotina nas ações e pedidos da Enfermagem ${ }^{(12)}$.

Ficar no leito o tempo todo, pouca comunicação, fala pouco, não tem atitude. Você fala: "Vamos deambular" e ele não saí do leito. Fica bem apático prostrado. Só quando você puxa conversa que fala, só quando você estimula que fala alguma coisa, só se vocêpedir. $\mathrm{Na}$ alimentação ficam inapetentes, não tem ânimo mesmo. Parece que as forças se foram. (E9)

As fases da raiva e da barganha foram identificadas com uma freqüência menor, sendo referidas em $46 \%$ e $23 \%$ das entrevistas, respectivamente. As atitudes de barganha e raiva são denotadas por alguns padrões como apego ao universo religioso e gestos confrontadores, respectivamente, como já fora observado por outros autores ${ }^{(1,5,15)}$.

Eles ficam um pouco mais rebeldes e não gostam muito de passar o creme hidratante. Vestem o pijama, mas é de qualquer jeito, ficam um pouco rebelde no sentido de tomar remédio, não ligam para o horário rigoroso. (E4)

Há fase em que eles se apegam na parte religiosa. Muito, muitos aqui mudam de religião. Começam a orar, tem biblia, vem pai e mãe e começam a orar, fazem esse tipo de coisa. (E4)

Nota-se que apenas dois (15\%) dos entrevistados explicitaram a percepção de todas as cinco fases do processo de morrer em suas falas. Apesar de demonstrarem essa habilidade, esses enfermeiros apresentaram dificuldades em relacionar os comportamentos e reações identificados com a descrição feita por Kübler-Ross ${ }^{(1)}$.

Constata-se que $12(92 \%)$ dos entrevistados expressaram em suas falas as fases melhor percebidas por eles na vivência com o paciente fora de possibilidades terapêuticas, sendo citadas, em média, três fases por enfermeiro, entre as cinco descritas.

Embora 92\% dos enfermeiros consigam perceber as 
fases do morrer em seus pacientes, 30\% não relacionam suas experiências com o conteúdo descritos por Kübler$\operatorname{Ross}^{(1)} ; 23 \%$ só relacionaram após terem pedido e recebido esclarecimentos, ao final das perguntas feitas (resgatando conhecimentos adquiridos anteriormente em algum momento de sua formação ou vida profissional) e só $46 \%$ relacionaram as fases que melhor identificam com a descrição da autora.

Entender cada fase identificada no paciente é importante para orientar ações e comportamentos no relacionamento enfermeiro-paciente, lembrando que não se pode generalizar o cuidado aos pacientes fora de possibilidades terapêuticas, principalmente em relação à identificação das fases do processo do morrer, que podem assumir um caráter meramente classificatório caso o enfermeiro não assuma os valores e experiências individuais de cada paciente que estiver sob seu cuidado.

A gente nunca se preocupou em classificar, entendeu? "Este está naquela fase" ou "Este está na outra fase"; a gente não. Talvez é certo, talvez não seja certo, talvez devêssemos, a gente não se preocupa em estar classificando. (E2)

A comunicação não-verbal na identificação das fases do processo de morrer

Em relação à comunicação não-verbal com pacientes em iminência de morte, nota-se que todos os enfermeiros entrevistados tiveram dificuldades para expressar quais eram os sinais, gestos e atitudes que eles traduziam na comunicação não-verbal dos pacientes terminais. Dizeres como "insatisfação", "tristeza", "desanimo" e "ansiedade" foram comumente utilizados para tentar explicar a percepção do enfermeiro a respeito das reações dos pacientes, sendo que há poucas minúcias de quais seriam os gestos que exprimem essa forma de decodificação. Das falas, sete (54\%) dos enfermeiros entrevistados puderam demonstrar quais sinais não-verbais denunciavam a fase do processo de morrer que identificaram nos pacientes sob seu cuidado.

Você detecta através de um tato, de um contato de aperto de mão, às vezes um reflexo de mímica facial... Eles transmitem isso pra você, e você percebe nitidamente esses desejos. Então fica assim, bem nitido. (E8)

Dentre os enfermeiros que relataram o uso da comunicação não-verbal, nota-se que a fase melhor percebida foi a depressão, por três $(23 \%)$ dos profissionais, através das posturas e gestos traduzidos como supracitado na sua forma de identificação.

Ficam no canto, tem uns que não querem nem falar! Eles não querem nada! Eles ficam num cantinho, se cobrem com um lençol, então você vai conversar e não querem. Eles preferem ficar com eles, dentro deles mesmo. (E5)

Percebe-se que todos os enfermeiros entrevistados demonstraram que suas ações estão intrinsecamente ligadas ao que observam nas atitudes dos pacientes, porém, poucos puderam traduzir como denotam a comunicação não-verbal quando interagem com o paciente sob seu cuidado.

A comunicação verbalizada, quando estabelecida, foi a base para o entendimento do processo vivenciado e percepção das fases do morrer para todos os enfermeiros da unidade. Em 100\% dos relatos nota-se que os profissionais valorizam a manutenção de uma comunicação verbal, pois referem que "o silêncio" ou "o chamar" são como um indicador "da vontade de viver" do enfermo.

Ele sabe que pode estar chegando a hora dele, e que a hora dele pode ser naquela noite, ou naquele dia. Então eles chamam, eles chamam bastante. Esse paciente chamava o tempo todo. (E5)

\section{CONCLUSÃO}

Os resultados do estudo indicam que os profissionais de Enfermagem encontram-se numa situação de fragilidade para atuar junto ao paciente fora de possibilidades terapêuticas. Alinhavando os dados obtidos aos objetivos do estudo percebe-se que existe uma lacuna evidente entre a formação do profissional e a manutenção do seu treinamento e suporte na instituição de saúde. É nítido que o cuidado às pessoas fora de possibilidades terapêuticas é resultado da dedicação e esforço desses profissionais que assumem um trabalho árduo, complexo e que demanda o domínio de muitas habilidades do enfermeiro para a sua efetivação.

Identifica-se que todos os profissionais já tiveram contato com as bases teóricas para o cuidado de pacientes terminais, mas os resultados da pesquisa demonstram uma baixa assimilação desse saber teórico à prática do enfermeiro. É importante lembrar que o local onde foi realizado o presente estudo é um hospital geral público vinculado ao ensino de profissionais de saúde, na cidade de São Paulo, e tem uma estrutura organizada e efetiva na Educação Continuada de seus funcionários. Mesmo assim, verifica-se o predomínio de profissionais que não relacionam os conteúdos científicos adquiridos à sua prática assistencial, pois não os consideram continuados e sistematizados.

Por outro lado, também percebe-se que o conteúdo fornecido na graduação desses profissionais não integra de forma significativa a bagagem de conhecimentos para o cuidado aos pacientes em cuidados paliativos. $\mathrm{Na}$ verdade, as ações dos enfermeiros, predominantemente, são resultados de suas experiências adquiridas na prática cotidiana do trabalho na referida unidade. Isso evidência 
que o currículo da graduação em Enfermagem nas faculdades não tem subsidiado qualitativamente as bases na formação de um saber voltado para o cuidado paliativo e preparo frente às situações de morte e morrer, exceto cursos extra-curriculares destinados à temática.

O despreparo profissional também está acompanhado do desamparo frente às tensões singulares existentes no trabalho do enfermeiro que presta cuidados aos pacientes fora de possibilidades terapêuticas. O sofrimento e dificuldades enfrentados emergiram das falas dos enfermeiros, trazendo à vista os conflitos e a realidade da equipe, evidenciando da falta de atenção à saúde e ao preparo desses cuidadores.

Esses profissionais atuam por meio da identificação e empatia ao paciente e suas necessidades, o que demanda mais esforços emocionais e psicológicos frente aos conflitos e tensões emergentes a cada interação. Assim, essa dificuldade traduz-se em emoções que podem dificultar a tarefa de assistir ao doente terminal, ou então, espoliar o profissional.

A comunicação com o paciente foi o aspecto em que os enfermeiros apresentaram maior dificuldade para demonstrar o seu conhecimento. Na síntese dos discursos, concluiu-se que sua prática está fortemente associada à percepção apurada que possuem dos gestos e sinais nãoverbais dos pacientes, mas que não conseguem traduzir como eles a percebem. Novamente associa-se esse fato à necessidade de apoio e instrumentalização do profissional para utilizar melhor a valiosa ferramenta que a comunicação se constitui nos cuidados paliativos.

A intervenção para os cuidados à uma morte digna depende da reavaliação dos currículos de formação dos enfermeiros, que carecem de uma abordagem mais expressiva sobre a temática da morte, morrer e luto. É necessário um investimento no preparo, aprimoramento continuado e formação especializada, assim como a implementação de serviços de psicologia nas instituições hospitalares e de saúde que possam oferecer apoio aos pacientes, familiares e profissionais, incrementando as potencialidades do enfermeiro como indivíduo e como profissional.

\section{REFERÊNCIAS}

1. Kübler-Ross E. Sobre a morte e o morrer. São Paulo: Martins Fontes; 1985.

2. Kóvacs MJ. Morte e desenvolvimento humano. São Paulo: Casa do Psicólogo; 1992.

3. Pessini L. Cuidados paliativos: alguns aspectos conceituais, biográficos e éticos. Rev Práticas Hospitalares. 2005; 41 (7): 107-12.

4. Pessini L. A filosofia dos cuidados paliativos: uma resposta diante da obstinação terapêutica. O Mundo da Saúde. 2003; 27 (1): 15-31.

5. Mccoughlan M. A necessidade de cuidados paliativos. $\mathrm{O}$ Mundo da Saúde 2003; 27 (1): 6-14.

6. Rodrigues IG. Cuidados paliativos: análise de conceito [tese]. São Paulo (RP): Escola de Enfermagem de Ribeirão Preto da USP; 2004.

7. Baraldi S. Sobre o significado da morte e do morrer identificando similaridades e diferenças no Brasil (São Paulo) e Cuba (Havana) [Tese]. São Paulo (SP): Programa de Pósgraduação em Integração da América Latina; 1999.

8. Paduan MA. A educação dos alunos de graduação em Enfermagem em relação à morte e ao morrer [Tese]. São Paulo (RP): Escola de Enfermagem de Ribeirão Preto; 1984.

9. Baraldi S, Silva MJP. Reflexões sobre a influência da estrutura social no processo da morte - morrer. Nursing. 2000; 24 (3): 14-17.

10. Silva MJP. Comunicação com o paciente fora de possibilidades terapêuticas. In: Humanização e cuidados paliativos. São Paulo: Loyola; 2004. cap. 16, p. 263-272.

11. Abelleira MAR, Fernández MJM, Couto EB, Martín MR, et al. Habilidades de comunicación para abordar el processo de la muerte. Enfermaría Científica. 1998; (198/199): 23-4.

12. Esslinger I. O paciente, a equipe e o cuidar: de quem é a vida afinal? In: Humanização e cuidados paliativos. São Paulo: Loyola; 2004. cap. 10, p. 149-62.

13. Silva MJP. Comunicação tem Remédio: a comunicação nas relações interpessoais em saúde. São Paulo: Loyola; 2005.

14. Bardin L. Análise de conteúdo. Lisboa: Edição 70; 1979.

15. Rodrigues $\mathrm{AB}$. Emoções e representações emergentes da experiência do olhar sobre a morte [Tese]. São Paulo: Escola de Enfermagem da USP; 2001. 